\title{
Melorheostosis of the Left Upper Limp
}

\author{
Bahri Evren $^{1}$, Ayse Cikim Sertkaya ${ }^{1}$, Ismail Koksal ${ }^{2}$, Ahmet Sigirci ${ }^{3}$, Ersoy Kekilli ${ }^{2 *}$ \\ ${ }^{1}$ Division of Endocrinology and Metabolism, School of Medicine, Inonu University, Malatya, Turkey \\ ${ }^{2}$ Department of Nuclear Medicine, School of Medicine, Inonu University, Malatya, Turkey \\ ${ }^{3}$ Department of Radiology, School of Medicine, Inonu University, Malatya, Turkey \\ Email: "ersoy.kekilli@inonu.edu.tr
}

Received June 20, 2012; revised July 22, 2012; accepted July 31, 2012

\begin{abstract}
Melorheostosis, also known as Leri disease or flowing periosteal hyperostosis, is a rare, non-hereditary, benign, sklerosing bone dysplasia which radiologically characterized by the appearance of "melting wax flowing down a candle". We report on a 43-year-old woman with melorheostosis who had pain in the upper limp for 10 years, limitation of joint movement and a deformity in the left third finger. Radiographies and bone scintigraphy were evaluated. All lesions of melorheostosis in radiography were seen in bone scintigraphy. More than half of increased uptakes on bone scintigraphy are due to degenerative process.
\end{abstract}

Keywords: Melorheostosis; Bone Scintigraphy; Radiography; Upper Limp

\section{Introduction}

Melorheostosis, also known as Leri disease or flowing periosteal hyperostosis, is a rare, non-hereditary, benign, sklerosing bone dysplasia which radiologically characterized by the appearance of "melting wax flowing down a candle” [1,2]. All bones may be affected, especially those of the lower limb. In the upper limb, this disease is rather unusual, and only a few cases have been reported in the humerus [4-10], and in the forearm and hand [3$7,11,12]$. Lesion localization is very important in the prevention of fracture, treatment and follow-up. Beside bone scintigraphy can easy detect of suspicious lesions in whole body, it can enables the detection of metabolically active lesions which is important the choice of treatment options, patient monitoring and the detection of lesions that cause clinical complaints [12].

\section{Case Report}

We report on a 43-year-old woman with melorheostosis who had pain in the upper limp for 10 years, limitation of joint movement and a deformity in the left third finger. Radiographies and bone scintigraphy were evaluated. Radiography showed "melting wax flowing down a candle" in left distal humerus and left fibula. Besides, sclerotic lesions were shown in left hand (ostriquetrum, oscapitatum, distal region of third metacarpal, third and forth proximal phalanges). Radiographies of the right upper

"Corresponding author. limbs were normal (Figure 1). All lesions of melorheostosis in radiography were seen in bone scintigraphy. More than half of increased uptakes of hands on bone scintigraphy are due to degenerative process. All lesions of melorheostosis in radiography were seen in bone scintigraphy. There is not excellent correlation in small bones between the scintigraphy and plain radiography for distribution of the lesions. More than half of increased uptakes on bone scintigraphy are due to degenerative process (Figure 2).

\section{Discussion}

The locations of melorheostosis can be shown with combined radiography, computerized tomography and radionuclide imaging. Magnetic resonance imaging can also be taken for the evaluation of soft tissue lesions and preoperative planning [5,13]. Increased radiopharmaceutical uptake is seen on bone scintigraphy. Some researchers reported that there are well correlation between bone scintigraphy and radiography $[7,14]$. Bone scintigraphy is a widely used and very sensitive imaging method for diagnosis and monitoring of bone lesions, but specificity is low [15]. In our case report more than half of increased uptakes of hands on bone scintigraphy are due to degenerative process. All radiographic lesions of melorheostosis were observed in bone scintigraphy. Except for hands, radiographic and scintigraphic localizations were similar in the upper extremity. Wesuggested that bone scintigraphy is very useful for the screening for suspicious lesions 


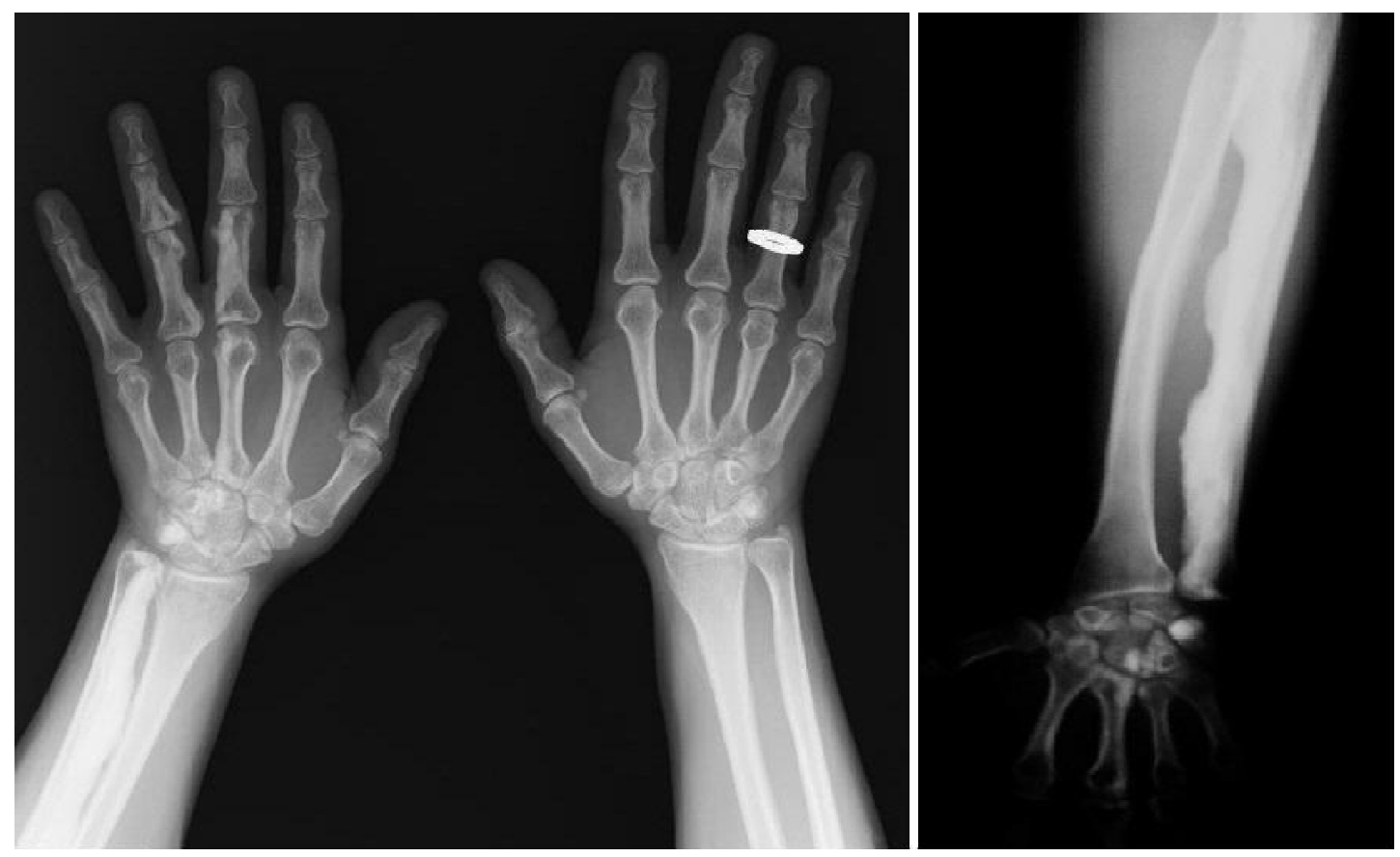

Figure 1. Radiography showed "melting wax flowing down a candle" in left distal humerus and left fibula. Besides, sclerotic lesions were shown in left hans (ostriquetrum, oscapitatum, distal region of third metacarpal, third and forth proximal phalanges).
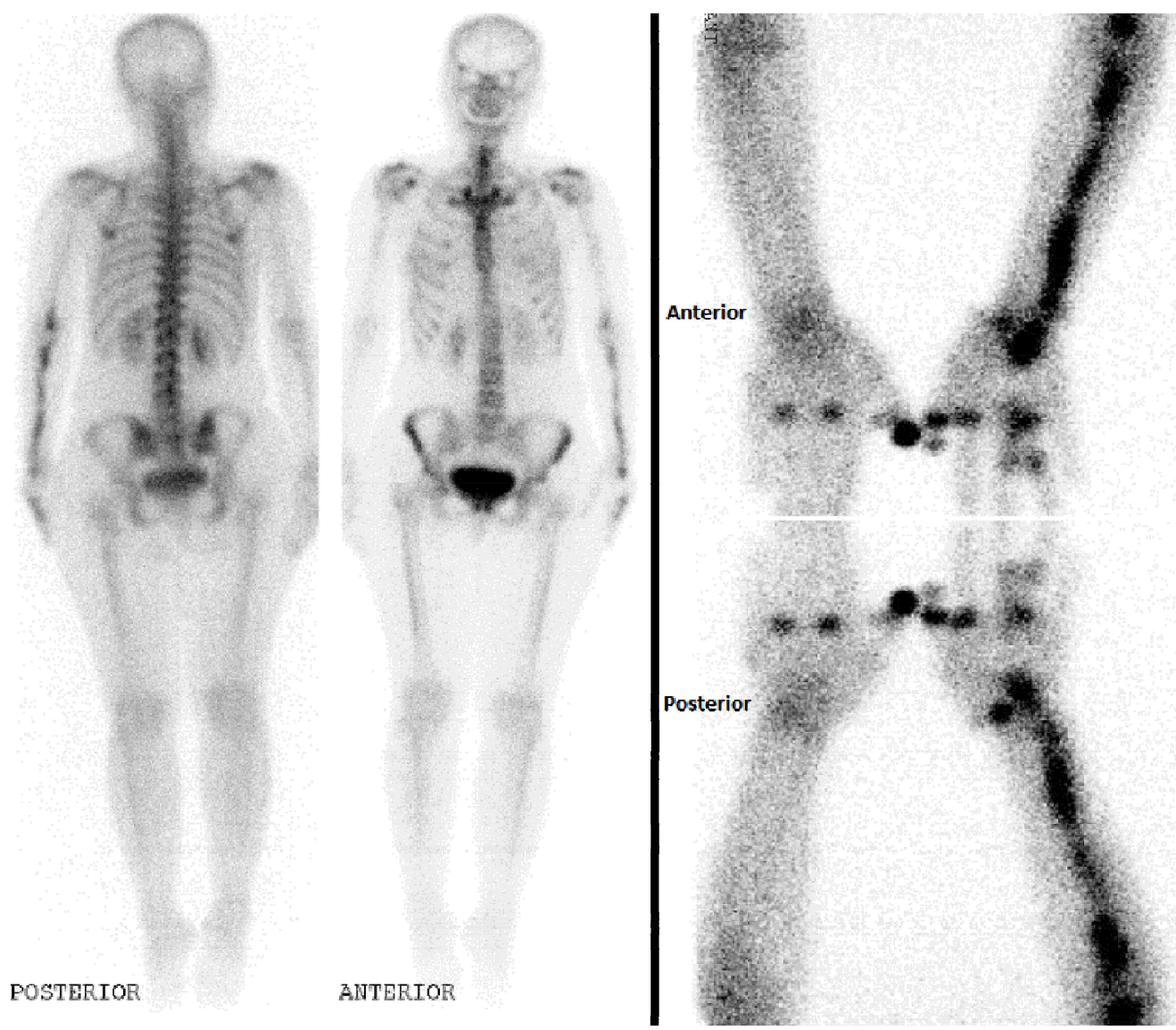

Figure 2. Bone scintigraphy showed additionally abnormal increased activity in left scaphoid bone, some metacarpophalangeal joints of both hands and first distal phalanges of right hand due to degenerative process. 
of melorheostosisin whole body but radiological methods are necessary for verification.

\section{REFERENCES}

[1] S. C. Zeiller, A. R. Vaccaro, D. W. Wimberley, T. J. Albert, J. S. Harrop and A. S. Hilibrand, "Severe Myelopathy Resulting from Melorheostosis of the Cervicothoracic Spine. A Case Report,” The Journal of Bone \& Joint Surgery, Vol. 87, No. 12, 2005, pp. 2759-2762. doi:10.2106/JBJS.D.02653

[2] C. J. Campbell, T. Papademetriou and M. Bonfiglio, "Melorheostosis. A Report of the Clinical, Roentgenographic and Pathological Findings in Fourteen Cases," The Journal of Bone \& Joint Surgery A, Vol. 50, No. 7, 1968, pp. 1281-1304.

[3] A. Al Kaissi, M. Skoumal, K. Roetzer, F. Grill and K. Klaushofer, “A Patient with Melorheostosis Manifesting with Features Similar to Tricho-Dento-Osseous Syndrome: A Case Report," Journal of Medical Case Reports, Vol. 19, No. 2, 2008, p. 51. doi:10.1186/1752-1947-2-51

[4] T. Murano and M. Egarian, "Case Report: Emergency Department Diagnosis of Melorheostosis in the Upper Extremity: A Rare Disease with an Unusual Presentation,” Journal of Emergency Medicine, Vol. 23, 2010.

[5] C. Yildirim, S. Ozyürek, E. I. Ciçek and M. Kuskucu, "Melorheostosis in the Upper Extremity," Orthopedics, Vol. 32, No. 4, 2009.

[6] O. Torbus, M. Jachimowicz, M. Pieta, A. Pikiewicz-Koch, M. Mielczarek and J. Glowacki, "Unusual Case of Mixed Sclerosing Bone Dysplasia in a 3.5-Year-Old Boy," WiadLek, Vol. 59, No. 9-10, 2006, pp. 720-723.

[7] T. Takeda, N. Ogura, S. Jodo, Y. Amasaki, T. Nakabayashi, K. Ichikawa, A. Tsutsumi, K. Ohnishi, A. Fujisakuand and S. Kobayashi, "A Case of Melorheostosis with linear Sclerodermatous Skin Changes,” Ryumachi, Vol. 35, No. 3, 1995, pp. 580-584.
[8] J. De Vos, A. Mulliez and G. De Loore, "Melorheostosis of the Humerus: A Rare Differential Diagnosis of carpal Tunnel Syndrome,” Chirurgie de la Main, Vol. 29, No. 2, 2010, pp. 125-127. doi:10.1016/j.main.2010.01.003

[9] S. G. Tueche, M. Gebhart, J. Dewolf, J. M. Baillon and J. M. Limbosch, "Cranio-Facial and humeral Melorrheostosis,” Acta Chirurgica Belgica, Vol. 99, No. 1, 1999, pp. 47-50.

[10] H. S. Gong, K. H. Lee, J. H. Oh, J. H. Chung, G. H. Baek and M. S. Chung, "Successful Elbow Contracture Release Secondary to Melorheostosis. A Case Report," The Journal of Bone \& Joint Surgery, Vol. 90, No. 5, 2008, pp. 1106-1111. doi:10.2106/JBJS.G.00961

[11] H. Azuma, T. Sakada, H. Tanabe and M. Handa "Melorheostosis of the Hand: A Report of Two Cases," The Journal of Hand Surgery, Vol. 17, No. 6, 1992, pp. 1076-1078. doi:10.1016/S0363-5023(09)91065-6

[12] R. J. Caudle and P. Stern, "Melorheostosis of the Hand. A Case Report with Longterm Follow-Up," The Journal of Bone \& Joint Surgery, Vol. 69, No. 8, 1987, pp. 12291231.

[13] A. M. Judkiewicz, M. D. Murphey, C. S. Resnik, A. H. Newberg, H. T. Temple and W. S. Smith, "Advanced Imaging of Melorheostosis with Emphasis on MRI,” Skeletal Radiology, Vol. 30, No. 8, 2001, pp. 447-453. doi:10.1007/s002560100366

[14] S. Izadyar and A. Gholamrezanezhad, "Bone Scintigraphy Elucidates Different Metabolic Stages of Melorheostosis,” The Pan African Medical Journal, Vol. 1, No. 11, 2012, p. 21.

[15] K. J. Donohoe, M. L. Brown, B. D. Collier, R. F. Carretta, R. E. Henkin and R. E. O’Mara, "Procedure Guideline for Bone Scintigraphy," Society of Nuclear Medicine Procedure Guideline Manual, 2003, pp. 205-209. http://interactive.snm.org/docs/pg_ch34_0403.pdf 